\title{
Specification of design wind loads in India
}

\author{
R NARASIMHA, U SHRINIVASA* \\ Centre for Atmospheric Sciences, Indian Institute of Science, Bangalore 560012, India \\ *Department of Mechanical Engineering
}

\begin{abstract}
Codes in current use in India for specifying design wind loads for structures are analysed, and shown to be inconsistent with available data on extremes. Thus, it is found that while the National Building Code specifies the highest wind loads on the east coast and western Gujarat, the observed extreme winds are highest in the eastern Gangetic valley. As the consequences of under-specification can be serious, a careful re-examination of the code seems called for. It is argued that although the available data on extremes may not be complete, they provide a more rational basis for formulating a building code; as wind loads become more important in construction engineering a serious effort at generating and analysing the required meteorological data seems highly worthwhile. However, procedures followed elsewhere for predicting extreme winds and the nature of gusts need to be validated for the country. In addition there is also a need to study certain meteorological phenomena peculiar to the Indian subcontinent like the duststorms and the nor'westers of north India.
\end{abstract}

Keywords. Design wind loads; National Building Code; extreme winds; risk analysis; wind engineering; wind energy.

\section{Introduction}

Wind loads and response to wind are important design parameters for many structures including bridges, high rise buildings, tall towers etc.; it is nowadays essential to ensure that such structures can survive the high winds and gusts likely to be encountered. This paper considers how these winds may be specified for India. Many countries including the Us, the UK, Australia etc. have in recent years reframed their respective national codes for wind and gust loads. The major reason for the change is that while the older versions were deterministic, the new codes are probabilistic, and make use of the statistics of extreme winds and risk analysis. No such exercise has been carried out for India so far. As of now, the National Building Code of India (NBC 1970) and the Indian Standards (IS 1965) provide maps of the country specifying 'design wind pressure' in various zones. There is however some analysis of extreme winds in India based on data from meteorological observatories (Sharma \& Sehgal 1968; Ayyar \& Goyal 1972; Mani \& Mooley 1983). We describe these data in $\$ 2$, and present a critical review in $\S 3$; some tentative suggestions for rewriting the code are made in $\$ 4$.

\section{Survey of data}

\section{$2.1 N B C$ specifications}

The NBC provides two wind pressure maps reproduced from is (1965) for the country. These specify a basic wind pressure which (after conversion to sI units by us) may be 
written as

$$
p=0.76 V^{2} \mathrm{~Pa}, V \text { in } \mathrm{m} / \mathrm{s} ;
$$

these pressures are stated to be "the maximum ever likely to occur in the respective areas under fully exposed conditions". One map includes "short duration winds", defined as those "which last only for a few minutes, generally less than 5 minutes"; the other excludes such winds. It appears, from the notes accompanying these maps, that the wind speeds expected during cyclones have played a major role in the formulation of the specifications.

The actual (static) load on any structure is then determined in terms of the basic pressure $p$, taking into account factors such as the geometry of the building. Corrections for heights exceeding $30 \mathrm{~m}$ are also provided in the notes.

\subsection{Extreme winds}

A second (and more satisfactory) approach would be to utilize extreme value statistics (eg Gumbel 1958) to specify wind speeds that are likely to be exceeded with stated probabilities in different parts of the country. Some analysis of data on such extreme winds (ie maximum wind speed during a year) in India is presented by Sharma \& Sehgal (1968), Ayyar \& Goyal (1972) and Mani \& Mooley (1983); they provide contours of extreme wind speeds corresponding to different specified "return periods".

This "return period" is defined as follows. If the probability of experiencing an extreme wind speed higher than $v$ in any one year is $1 / T$ (ie if $P(V>v)=1 / T$ ), then $T$ is called the return period for the wind speed $v$. The probability of interest to the designer is that of encountering at least one extreme of specified value in the period $T$; this probability is

$$
1-(1-1 / T)^{T}, \rightarrow 1-e^{-T} \text { as } T \rightarrow \infty .
$$

For a given risk of exceedence during the life of a structure, the return period required can be worked out.

Contours of extreme wind speeds obtained by Ayyar \& Goyal and Mani \& Mooley are based on data on annual peak gust wind speeds from Dines pressure tube anemographs from 24 and 18 stations respectively spread over the country. The basic wind speeds used in the analysis are obtained from anemometers at different heights above ground; no corrections were applied for height, terrain or exposure. The data have been fitted to a Fisher-Tippett Type I distribution, which gives, for the probability that the extreme wind speed $V$ is less than $v$; the value

$$
P(V<v)=\exp [-\exp -((v-\mu) / \sigma)],
$$

where $\mu$ is a location parameter and $\sigma,>0$, a scale parameter. On the other hand Sharma \& Sehgal analysed similar data from only 7 stations in north India. They have corrected their anemometer readings for variations in height and fitted their data to the same distribution (which they call the Gumbel distribution).

Figure 1 shows the 100 year return period contours of Ayyar \& Goyal superposed over the NBC map which includes short duration winds. It will be noticed that, according to Ayyar \& Goyal, the highest winds are experienced not along the east coast as indicated by NBC, but in the eastern Gangetic valley. They suggest in explanation that "the short-period squally winds associated with the thunderstorms and the duststorms 


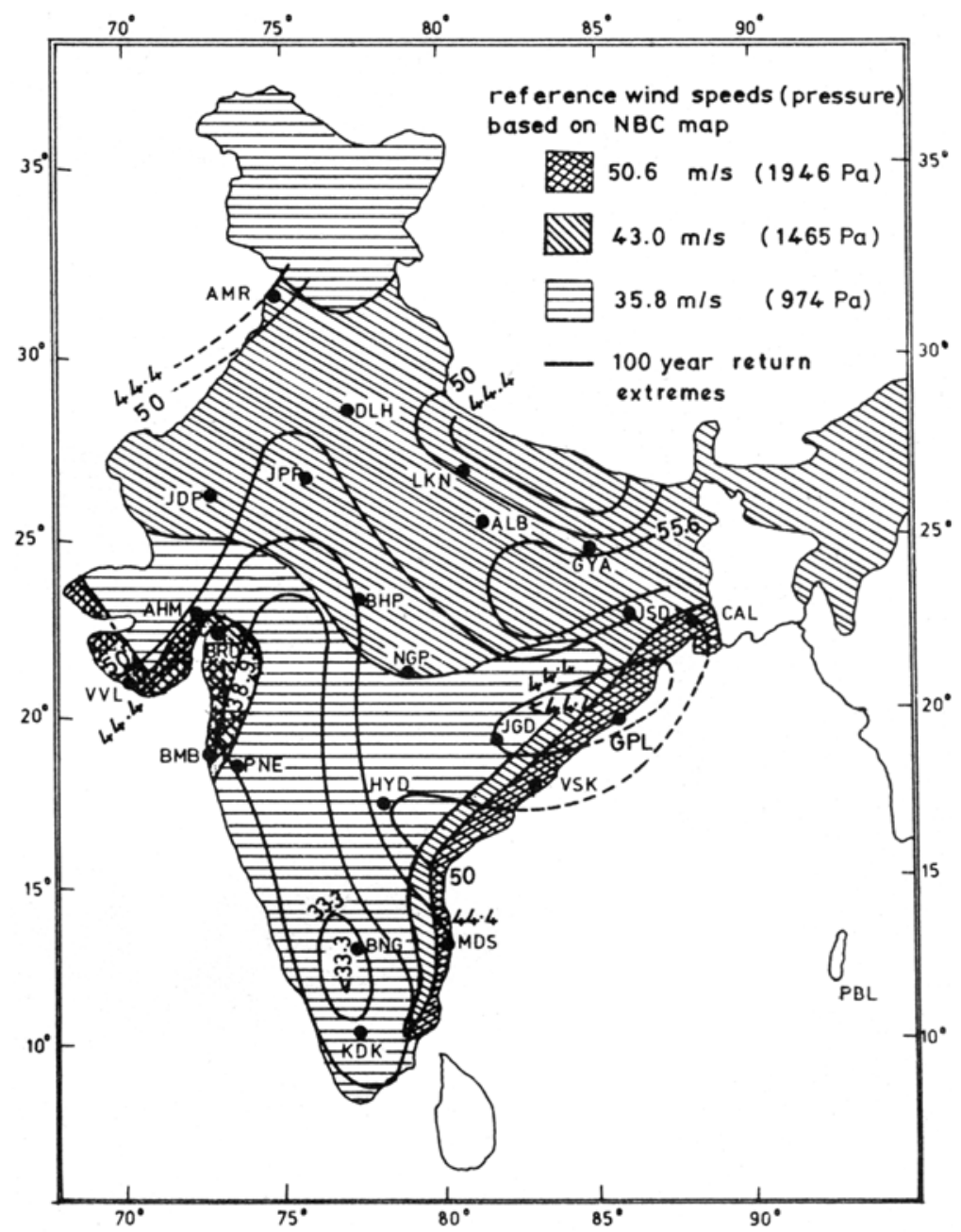

Figure 1. Reference wind speeds ( $\mathrm{m} / \mathrm{s}$ ) and wind pressure ( $\mathrm{Pa}$ ) based on NBC map, compared with contours of extremes (Ayyar \& Goyal 1972) for a 100 yr return period.

of north India are stronger than even the gales associated with cyclonic storms which affect the coastal regions”. This view is also supported by Mani \& Mooley (1983). Although their contours of extreme wind speeds (see figure 2 for comparison) do not completely coincide with those of Ayyar \& Goyal, there is general agreement among all three analyses on one important message, $i e$ that the highest values for the extremes are found in the eastern Gangetic valley.

\section{Critical review}

\subsection{The National Building Code}

3.1a Non-probabilistic nature of specification: The NBC specification of design wind loads is entirely deterministic; this is unsatisfactory, as the concept of "the maximum 


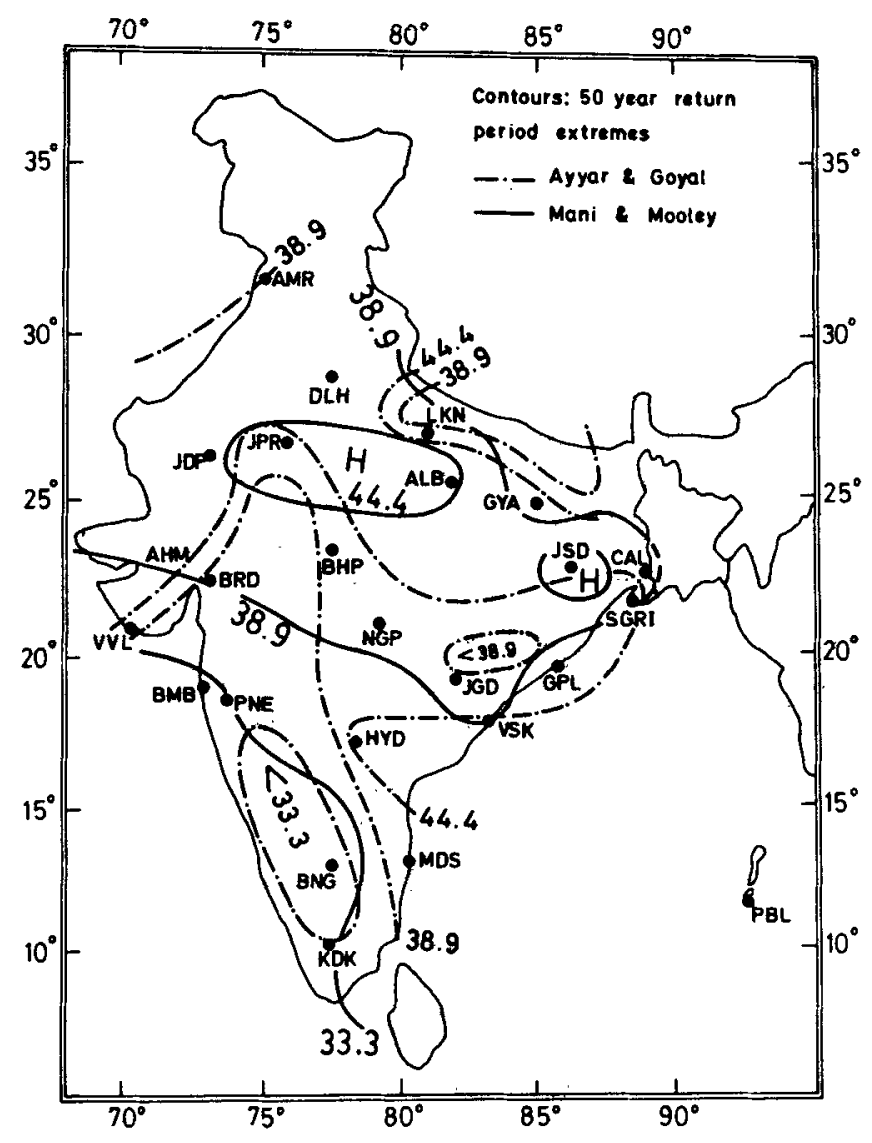

Figure 2. Comparison of contours of 50 yr return period extremes from Ayyar \& Goyal (1972) and Mani \& Mooley (1983).

(wind) ever likely to occur" cannot be justified, and does not in general lead to well defined numbers. The maximum wind experienced at a site increases with the duration of observations. It is for this reason that a probabilistic specification is necessary (see eg Lawson 1980).

3.1b Variation with height-effect of terrain: The variation of wind pressure with height, $z$, as laid down by the code, corresponds to the law

$$
V(z) \propto z^{1 / n}
$$

the value of $n$ implicit in the Code is about 10 (Narasimha \& Shrinivasa 1983). A statement is made in the Code that the specifications apply to fully exposed conditions, and that the values indicated "should be modified according to the local conditions because the surface wind is known to depend markedly on the local topography, etc". No guidance is available, however, on how the effects of topography can be taken into account.

3.1c Averaging times: As already mentioned, the NBC maps respectively include and exclude "short-duration winds", defined as those which last "only for a few minutes, 
generally less than 5 minutes". Gust speeds depend continuously on the averaging time used in a manner that depends on the terrain (Simiu 1977); the averaging time that is appropriate for use in structural design should be close to the natural period of the structure, which is generally of the order of seconds or fractions of a second rather than minutes. The wind speeds used for the Code may therefore need modification to take this factor into account.

3.1d Value of basic wind pressure: The basis for the formula for the pressure in (1) is not known. The dynamic pressure at wind speed $V$ is given by

$$
P_{d}=\frac{1}{2} \rho V^{2}=0.58 V^{2} \mathrm{~Pa},
$$

if $V$ is in $\mathrm{m} / \mathrm{s}$; here $\rho$ is taken as $1 \cdot 155 \mathrm{~kg} / \mathrm{m}^{3}$, which is appropriate to the mean condition in tropical India (Ananthasayanam \& Narasimha 1980). The 'basic wind pressure' of NBC is thus about $30 \%$ higher than the dynamic pressure at the same wind velocity.

3.1e Comparison with data on extremes: As already noted, the Code quotes only a basic wind pressure $p$, in terms of which structural loads are determined; no basic wind speed as such is explicitly specified. However, we can determine a reference wind speed defined as

$$
V_{\text {ref }}=(p / 0.76)^{1 / 2} \mathrm{~m} / \mathrm{s}, p \text { in } \mathrm{Pa} ;
$$

values of $V_{\text {ref }}$ are shown in figure 1 , and are compared with the 100 year return period winds of Ayyar \& Goyal. The numbers are different, but this is not surprising, as the concepts of return period and reference velocity are not used in the Code. What is more significant is that the zone of high extremes is quite different from the areas where the Code specifies the highest wind loads. In other words, the Code and the available data on extremes are inconsistent with each other.

We shall consider the data on extremes in the next section.

\subsection{Extreme wind data}

$3.2 a$ Nature of regional variation: The eastern Gangetic valley, where extreme winds are the highest, experiences many storms other than cyclones moving in from the Bay of Bengal; these cyclones are weakened considerably by the time they move so far inland. Such other storms include thunder- and duststorms and nor'westers (kal baisakhis). The extremes over the rest of the country show some correlation with the orography (see figure 3). In general wind speeds attenuate rapidly inland especially where the cyclones responsible for the winds encounter hilly terrain; where a gap in a hill-chain reduces the attenuation the contours for the extremes protrude far inland, as eg the one around Hyderabad in figure 1. Many other similarities between the extreme contours and the orography are apparent from figure 3.

3.2b Distributions used: As already stated, all authors who have studied extreme winds in India have used the Fisher-Tippet distribution, Type I. Although this is one of the standard asymptotic laws governing extremes (Gumbel 1958), there is much evidence, especially in the tropics, that the distribution is often mixed. For example, Thom (1967) finds that, where both tropical and extra-tropical disturbances are experienced, the distribution tends to be of the type

$$
P(V<v)=P_{T} \exp \left[-(v / \sigma)^{-4 \cdot 5}\right]+\left(1-P_{T}\right) \exp \left[-(v / \sigma)^{-9.0}\right]
$$




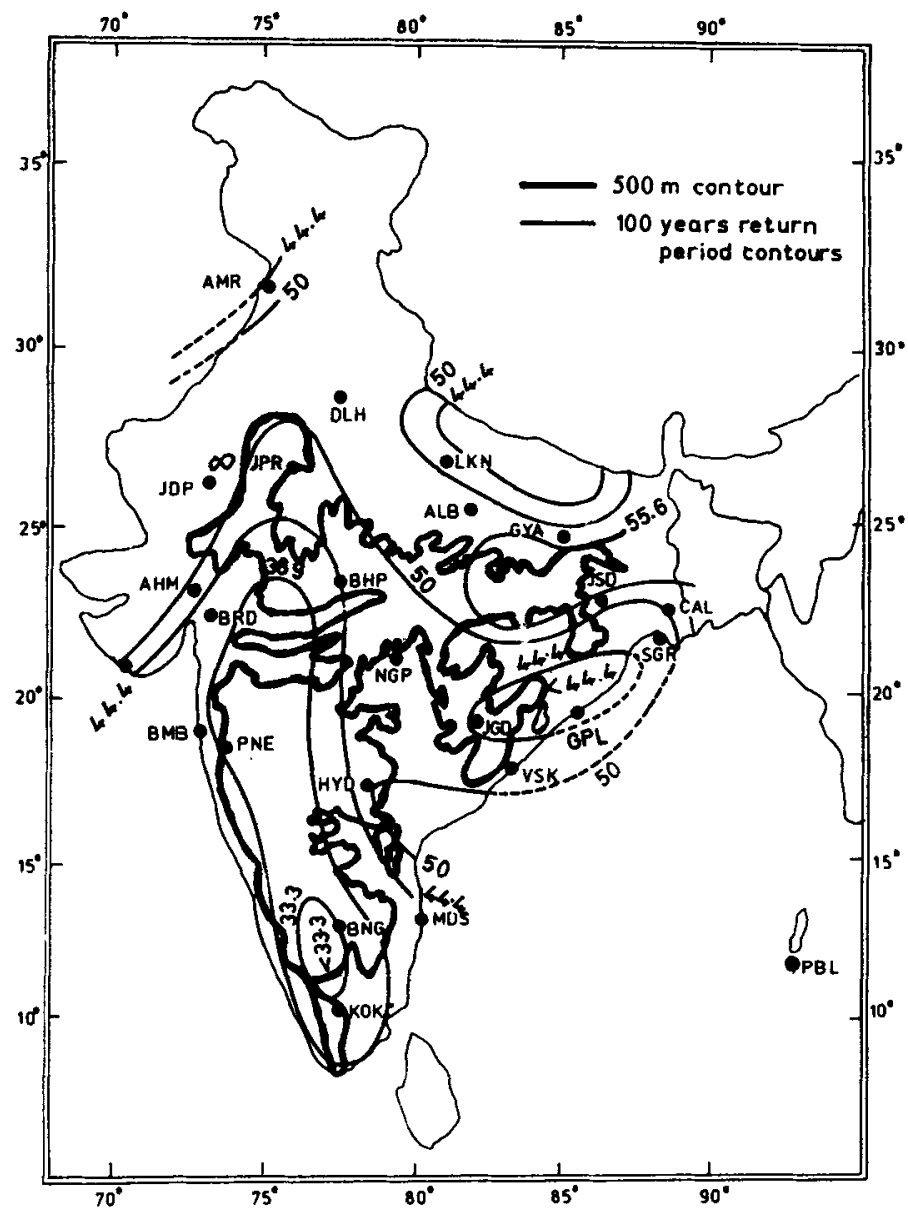

Figure 3. Contours of extremes (Ayyar \& Goyal 1972) for a 100 yr return period compared with orographic features

where $P_{T}$ and $\left(1-P_{T}\right)$ are associated with the probabilities of tropical and extra-tropical cyclones respectively. Even where $1-P_{T}=0$, the distribution, according to Thom, is of the Fisher-Tippett Type II rather than Type I. Unfortunately, no information is available on the goodness of fit of the distribution adopted in India to the available data.

Figure 4 shows the results of some analysis made by the present authors (Narasimha \& Shrinivasa 1983) using the Fisher-Tippett Type I distribution and extreme wind data from IMD for four additional stations. The distribution seems to fit the data very well with a correlation co-efficient larger than 0.9 for the straight line $V_{T}=a+b y(T)$ where $V_{T}$ is the extreme wind speed with a return period of $T$ years and $y(T)$ is the reduced variate (defined in table 4).

3.2c Height, exposure: The Indian data on extremes have often not been corrected for height and exposure; although certain procedures for such correction have now been formulated (eg ESDU 1972; Shrinivasa 1984) these have not been validated by any 


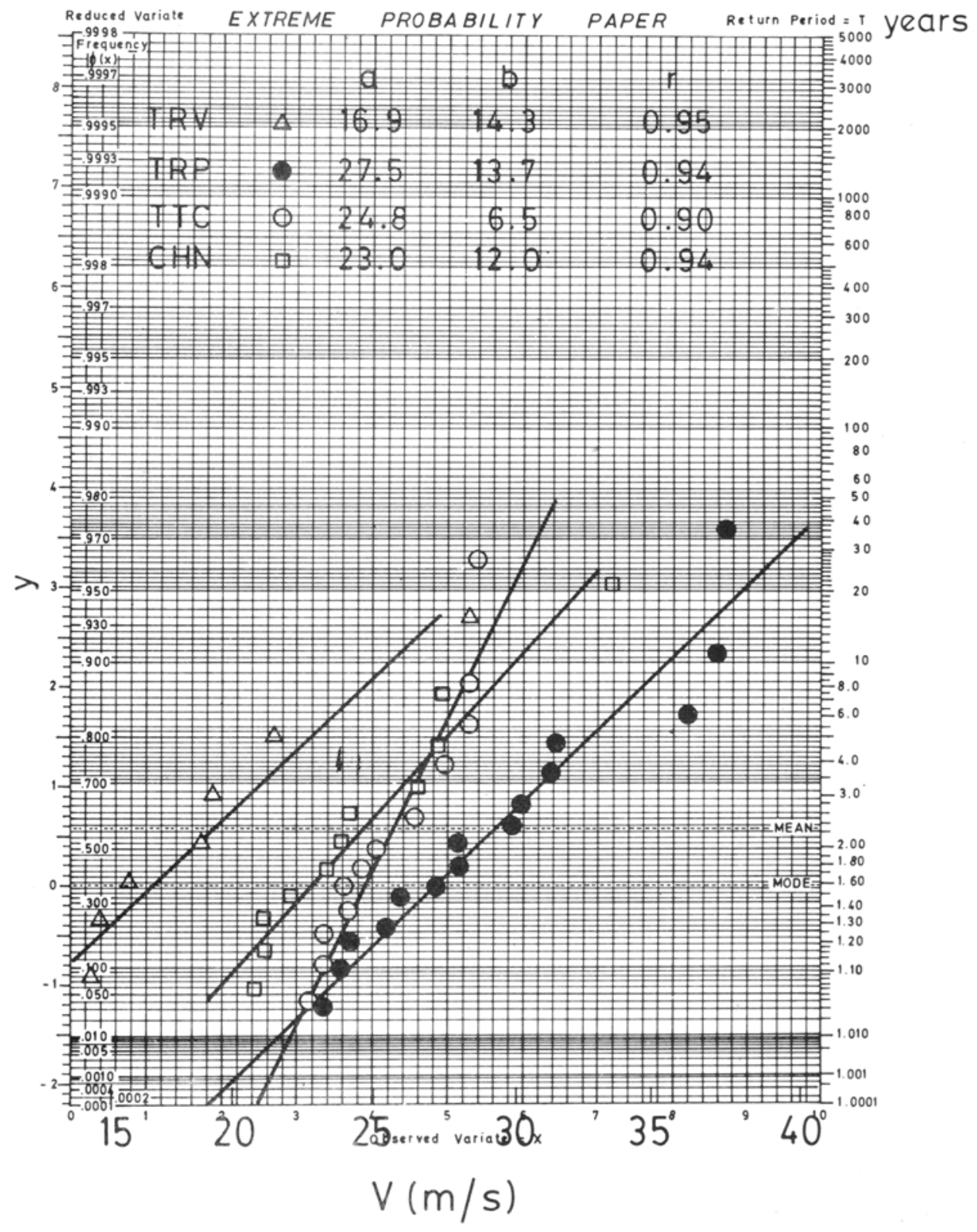

Figure 4. Some extreme wind speed data $V_{i}=a+b y_{i}, V_{i}$ is the $i$ th smallest annual extreme wind speed from available data, $y_{i}=\ln (-\ln ((i-1 / 2) / n)) ; n$ is the number of annual extreme wind speed data points and $r$ is the correlation coefficient between $V_{i}$ and $y_{i}$. CHN-Cochin, TRPTiruchirapalli, TRV-Trivandrum, TTC-Tuticorin 
Indian data, and furthermore the required information on characteristics of the surrounding terrain are not available.

\subsection{Comparisons}

Figure 1 has already compared Ayyar \& Goyal's data on extremes with the reference speeds implied by NBC; the four sets of analysis (table 1) on extreme winds now available do not always agree with one another; in 16 cases the differences are greater than $5 \mathrm{~m} / \mathrm{s}$ and in two cases it is as high as $14 \mathrm{~m} / \mathrm{s}$. These discrepancies need to be resolved. It is not easy, without further studies, to determine at the present time the causes for these discrepancies; but we note that there is general agreement on the broad nature of variation of extremes over the country.

Table 1. Comparison of 50 year return period extremes $(\mathrm{m} / \mathrm{s})$ predicted by various authors.

\begin{tabular}{|c|c|c|c|c|}
\hline Station & $\begin{array}{c}\text { Sharma } \\
\text { \& Sehgal } \\
\text { (1968) }\end{array}$ & $\begin{array}{c}\text { Ayyar } \\
\text { \& Goyal } \\
\text { (1972) }\end{array}$ & $\begin{array}{c}\text { Mani } \\
\text { \& Mooley } \\
(1983)\end{array}$ & $\begin{array}{c}\text { Narasimha } \\
\text { \& Shrinivasa } \\
\text { (1983) }\end{array}$ \\
\hline Ahmedabad & - & $45 \cdot 8$ & $40 \cdot 8$ & - \\
\hline Allahabad & $44 \cdot 7$ & $49 \cdot 4$ & $46 \cdot 4$ & - \\
\hline Amritsar & 一 & $40 \cdot 8$ & - & - \\
\hline Bangalore & - & $31 \cdot 4$ & $28 \cdot 1$ & - \\
\hline Baroda & - & $26 \cdot 1$ & $40 \cdot 0^{*}$ & - \\
\hline Bhopal & $35 \cdot 6$ & 36.9 & $43 \cdot 0^{*}$ & - \\
\hline Bombay & - & $37 \cdot 2$ & $30 \cdot 8$ & - \\
\hline Calcutta & - & 45.8 & 41.9 & - \\
\hline Cochin & 一 & $36 \cdot 0^{*}$ & $28 \cdot 0^{*}$ & $36 \cdot 1$ \\
\hline Gaya & - & $42 \cdot 5$ & 36.4 & - \\
\hline Gopalpur & - & $42 \cdot 5$ & $31 \cdot 7$ & - \\
\hline Hyderabad & - & $45 \cdot 6$ & $360^{*}$ & - \\
\hline Jagdalpur & - & $37 \cdot 2$ & $40 \cdot 0^{*}$ & - \\
\hline Jaipur & $35 \cdot 0$ & 43.9 & $45 \cdot 0^{*}$ & - \\
\hline Jamshedpur & - & $51 \cdot 4$ & $48 \cdot 6$ & - \\
\hline Jodhpur & 34.4 & $48 \cdot 6$ & $44 \cdot 2$ & - \\
\hline Kodaikanal & - & $33 \cdot 6$ & 33.6 & - \\
\hline Lucknow & 36.7 & $38 \cdot 1$ & $43 \cdot 0^{*}$ & - \\
\hline Madras & - & $40 \cdot 6$ & $35 \cdot 3$ & - \\
\hline Nagpur & $38 \cdot 1$ & $43 \cdot 6$ & $41 \cdot 1$ & - \\
\hline New Delhi & $41 \cdot 4$ & $47 \cdot 8$ & $42 \cdot 2$ & - \\
\hline Pune & - & $38 \cdot 6$ & $35 \cdot 6$ & - \\
\hline Port Blair & - & $39 \cdot 7$ & - & - \\
\hline Sagar Island & - & 40.8 & $38 \cdot 3$ & - \\
\hline Tiruchirapalli & - & $39 \cdot 0^{*}$ & $35 \cdot 0^{*}$ & $43 \cdot 3$ \\
\hline Trivandrum & - & $36 \cdot 0^{*}$ & $300^{*}$ & $32 \cdot 8$ \\
\hline Tuticorin & - & $36 \cdot 0^{*}$ & $33.0^{*}$ & $32 \cdot 0$ \\
\hline Veraval & - & $39 \cdot 7$ & $36 \cdot 0^{*}$ & - \\
\hline Vishakhapattinam & - & $45 \cdot 0^{*}$ & $38 \cdot 3$ & - \\
\hline
\end{tabular}

*Values estimated from the maps provided by the authors. 


\section{Implications for wind engineering}

\subsection{Wind energy}

Figure 5 shows contours of equal mean winds in India from Narasimha \& Shrinivasa (1983) superposed on Ayyar \& Goyal's contours of equal 50-year-return extremes. For comparison, figure 6 shows a similar plot for the us (Narasimha \& Shrinivasa 1983).

From these figures, it is clear that the ratio of extreme to mean winds is lower over a larger part of the us than India-about $50 \%$ of the land area of the us experiences an extreme/mean ratio less than 10 , whereas in India the corresponding fraction is only $15 \%$. On the other hand about $50 \%$ of India experiences an extreme/mean ratio greater than 15. A high extreme demands a stronger structure (highest predicted values of 50 year return extreme for the two countries are about $50 \mathrm{~m} / \mathrm{s}$ ), and a low mean implies little energy in the wind for extraction (nearly $30 \%$ of us has annual means exceeding about $6 \mathrm{~m} / \mathrm{s}$ whereas India has no such areas); clearly the windmill designer would like as low a value for the extreme/mean ratio as possible. If the data in figure 5 can be

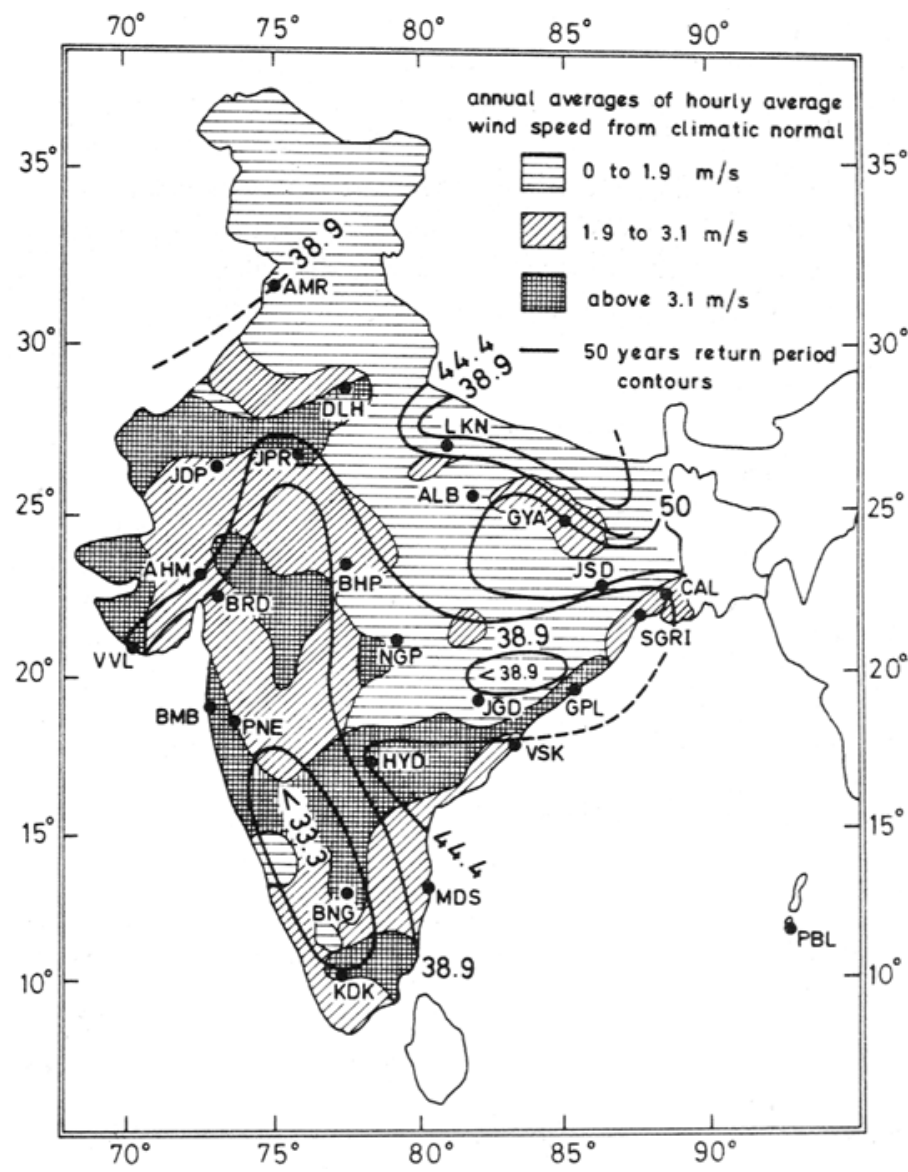

Figure 5. Contours of equal mean wind speeds in $\mathrm{m} / \mathrm{s}$ (Narasimha \& Shrinivasa 1983) and 50 yr return extremes (Ayyar \& Goyal 1972) 


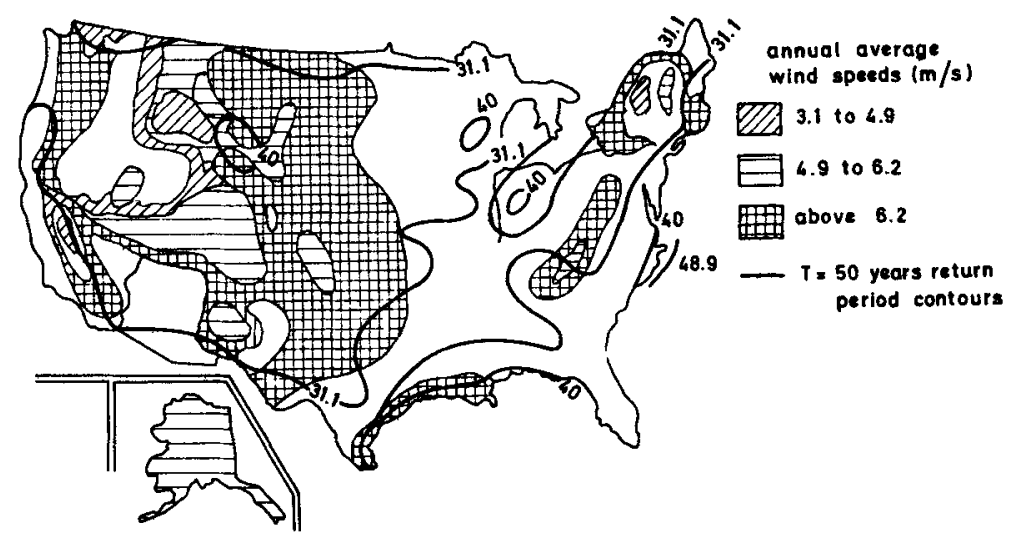

Figure 6. Contours of mean wind speeds and $50 \mathrm{yr}$ return extremes for the uSA (Source: Mikhail 1981) (from Narasimha \& Shrinivasa 1983)

trusted, the eastern Gangetic valley, with high extreme/mean ratio and low mean, is the area least suited to extraction of wind energy in India. Table 2 lists means and extremes for some regions in the country. It so turns out that in India, means and extremes are totally uncorrelated; for the 28 stations listed in table 2 the correlation coefficient turns out to be 0.0006 . Table 3 provides the probability of failure, within 20 years of construction, for structures designed for three specified wind speeds (Narasimha \& Shrinivasa 1983). These have been obtained using the formula

$$
P_{f}=1-[\exp -(\exp -((V-a) / b))]^{20}
$$

where $V$ is the design wind speed and $a$ and $b$ are taken from table 4 . If one specifies a design life of 20 years with a $20 \%$ risk of loss, or of 10 years with a $10 \%$ risk, it can be seen from table 5 that the extreme wind speeds for the return period of interest is almost 100 years. (As can be seen from table 5, these risks correspond to return periods of 90 and 95 years respectively, and we have rounded these off to 100 years). Design wind speeds for any other return period $T$ could be tentatively obtained using the formula

$$
V_{T}=a+b(-\ln (-\ln (1-(1 / T)))
$$

(Lawson 1980) where $a$ and $b$ are given in table 4.

\subsection{Construction engineering}

Current procedures for the determination of design wind speeds involve the following basic steps (ESDU 1972):

Step 1: Determine desired life of structure (ie select the value of acceptable risk of failure at the end of specified life).

Step 2: For this risk, determine the corresponding return period (table 5).

Step 3: From the available meteorological data, determine a "standard maximum wind speed" at the site. (The standard applies for an accepted height, usually $10 \mathrm{~m}$, accepted averaging time (either $2 \mathrm{~s}$ or $1 \mathrm{hr}$ ) and accepted terrain ("flat and open").) 
Table 2. Mean and extreme wind speeds

\begin{tabular}{|c|c|c|c|c|c|}
\hline \multirow[b]{2}{*}{ Station } & \multirow{2}{*}{$\begin{array}{l}\text { Mean wind } \\
\text { speed }(\mathrm{m} / \mathrm{s})\end{array}$} & \multicolumn{3}{|c|}{$\begin{array}{c}\text { Extreme wind speed }(\mathrm{m} / \mathrm{s}) \text { at } \\
\text { return period }(\mathrm{yr})\end{array}$} & \multirow{2}{*}{$\begin{array}{c}100 \text { years } \\
\text { extreme/ } \\
\text { mean }\end{array}$} \\
\hline & & 20 & 50 & 100 & \\
\hline Ahmedabad & 1.9 & $40 \cdot 2$ & 45.8 & $50 \cdot 0$ & $26 \cdot 3$ \\
\hline Allahabad & 1.8 & $43 \cdot 3$ & $49 \cdot 8$ & 53.9 & $30 \cdot 3$ \\
\hline Amritsar & $2 \cdot 4$ & $39 \cdot 2$ & 40.8 & 41.9 & $17 \cdot 5$ \\
\hline Bangalore & $3 \cdot 2$ & $29 \cdot 2$ & $31 \cdot 4$ & $33 \cdot 1$ & $10-3$ \\
\hline Baroda & 1.5 & $24 \cdot 2$ & $26 \cdot 1$ & 27.5 & $18 \cdot 9$ \\
\hline Bombay & $2 \cdot 9$ & 33.9 & 37.2 & $39 \cdot 7$ & $13 \cdot 7$ \\
\hline Bhopal & $2 \cdot 3$ & $34 \cdot 2$ & $36 \cdot 9$ & $39 \cdot 2$ & 16.9 \\
\hline Calcutta & $1 \cdot 4$ & 41.9 & $45 \cdot 8$ & 48.6 & $16 \cdot 9$ \\
\hline Cochin* & 2.5 & $32: 8$ & $36 \cdot 1$ & $38 \cdot 6$ & $15 \cdot 4$ \\
\hline Gaya & $2 \cdot 4$ & $38 \cdot 3$ & 42.5 & $45 \cdot 3$ & $18 \cdot 9$ \\
\hline Gopalpur & $4 \cdot 2$ & $38 \cdot 3$ & $42 \cdot 5$ & $45 \cdot 3$ & 10.9 \\
\hline Hyderabad & $3 \cdot 5$ & $40 \cdot 6$ & 45.6 & $49 \cdot 2$ & $14 \cdot 3$ \\
\hline Jagdalpur & $1 \cdot 4$ & $33 \cdot 6$ & $37 \cdot 2$ & 40.0 & $27 \cdot 8$ \\
\hline Jaipur & 3.4 & 38.6 & 43.8 & $48 \cdot 1$ & $14 \cdot 1$ \\
\hline Jamshedpur & 1.5 & 45.8 & 51.4 & 55.4 & 37.0 \\
\hline Jodhpur & 3.0 & $43 \cdot 3$ & 48.6 & 52.7 & $17 \cdot 5$ \\
\hline Kodaikanal & $3-6$ & $31 \cdot 3$ & $33 \cdot 6$ & $35 \cdot 3$ & 9.8 \\
\hline Lucknow & 0.9 & $34 \cdot 7$ & $38 \cdot 1$ & $40 \cdot 6$ & 50.0 \\
\hline Madras & $3 \cdot 3$ & $36 \cdot 4$ & $40 \cdot 6$ & 43.6 & $13 \cdot 3$ \\
\hline Nagpur & - & $39 \cdot 7$ & 43.6 & $46 \cdot 7$ & - \\
\hline New Delhi & $2 \cdot 7$ & $42 \cdot 5$ & 47.8 & $51 \cdot 1$ & $18 \cdot 9$ \\
\hline Pune & 1.5 & $34 \cdot 7$ & $38 \cdot 6$ & $41 \cdot 4$ & $28 \cdot 6$ \\
\hline Port Blair & $3 \cdot 8$ & $36 \cdot 7$ & $39 \cdot 7$ & $42 \cdot 2$ & $12 \cdot 5$ \\
\hline Sagar Island & $5 \cdot 2$ & 37.5 & 40.8 & $43 \cdot 3$ & $8 \cdot 3$ \\
\hline Tiruchirapalli* & $4 \cdot 4$ & $39 \cdot 7$ & $43 \cdot 3$ & $46 \cdot 4$ & $10 \cdot 5$ \\
\hline Trivandrum* & $2 \cdot 2$ & $28 \cdot 9$ & $32 \cdot 8$ & $35 \cdot 8$ & $16 \cdot 4$ \\
\hline Tuticorin* & $4 \cdot 7$ & $30 \cdot 0$ & $32 \cdot 0$ & 33.0 & $7 \cdot 1$ \\
\hline Veraval & $4 \cdot 6$ & $36 \cdot 1$ & $39 \cdot 7$ & 42.5 & $9 \cdot 3$ \\
\hline
\end{tabular}

The line of best fit between the 2 nd and the 5 th columns is $V_{100}=43.09+0.14 V_{m}$; correlation coefficient between $V_{100}$ and $V_{m}$ is 00006; extreme wind speeds are from Ayyar \& Goyal (1972) except for the four stations marked with * for which they have been obtained from Narasimha \& Shrinivasa (1983).

Step 4: Using specified procedures, eg the data of table 6 and figure 7, correct for height, averaging time and terrain at site as they apply to the structure being designed. Step 5: If the size of structure is greater than about $30 \mathrm{~m}$, apply another special correction (as described $e g$ in ESDU 1972).

If the dynamic response of the structure to turbulence is also to be analysed, additional data are necessary; they will be considered separately. Unfortunately, the site data required for the above procedures are not yet available in India. However, based on available information on extremes we propose tentatively two extreme wind zone maps here (figures $8 \& 9$ ) for the 50 year and the 100 year return periods respectively. The criteria adopted in drawing these maps are the following.

(i) Where there is disagreement on the precise value of the extreme, make a conservative (ie safe) choice.

(ii) Use linear interpolation between neighbouring stations in drawing contours. 
Table 3. Failure probability of structures during their desired life span of $20 \mathrm{yr}$

\begin{tabular}{|c|c|c|c|}
\hline \multirow[b]{2}{*}{ Station } & \multicolumn{3}{|c|}{ Design wind speed $(\mathrm{m} / \mathrm{s})$} \\
\hline & $33 \cdot 3$ & $44 \cdot 4$ & $55 \cdot 6$ \\
\hline & \multicolumn{3}{|c|}{ Failure probability } \\
\hline Ahmedabad & 0.965 & 0.407 & 0.078 \\
\hline Allahabad & 0.993 & 0.590 & 0.148 \\
\hline Amritsar & 1.000 & $0-047$ & 0.001 \\
\hline Bangalore & 0.172 & 0.002 & 0.001 \\
\hline Baroda & 0.003 & 0.001 & 0,000 \\
\hline Bhopal & 0.770 & 0.036 & 0.001 \\
\hline Bombay & 0.715 & 0057 & 0.003 \\
\hline Calcutta & 0.999 & $0-438$ & $0-037$ \\
\hline Cochin & 0.540 & 0.040 & $0-002$ \\
\hline Gaya & 0.971 & 0.227 & 0.019 \\
\hline Gopalpur & 0.970 & 0.227 & 0019 \\
\hline Hyderabad & 0.982 & 0.400 & 0.063 \\
\hline Jagdalpur & 0.667 & 0.067 & 0.005 \\
\hline Jaipur & 0.997 & 0.728 & 0.187 \\
\hline Jodhpur & 0.998 & 0.578 & $0-119$ \\
\hline Kodaikanal & 0.383 & 0.005 & 0.001 \\
\hline Lucknow & 0.808 & 0.072 & 0.004 \\
\hline Nagpur & 0.874 & 0.154 & $0-014$ \\
\hline New Delhi & 0.999 & 0.567 & 0.079 \\
\hline Pune & 0.771 & 0.093 & $0-007$ \\
\hline Port Blair & 0.942 & 0.101 & 0.004 \\
\hline Sagar Island & 0.971 & 0.147 & 0.008 \\
\hline Tiruchirapalli & 0.990 & 0.270 & 0.020 \\
\hline Trivandrum & 0.300 & 0.020 & 0.000 \\
\hline Tuticorin & 0.330 & 0.001 & 0.000 \\
\hline Veraval & 0.879 & 0.112 & 0.007 \\
\hline
\end{tabular}

(iii) Select the number of zones to be specified so that the distinction between them stands out above the uncertainties in the data.

We indicate the lowest safe values for each station in Table 7. With the acquisition of more data and the use of consistent analysis, the values in this table and also the boundaries of the different zones would almost certainly be modified, but we expect

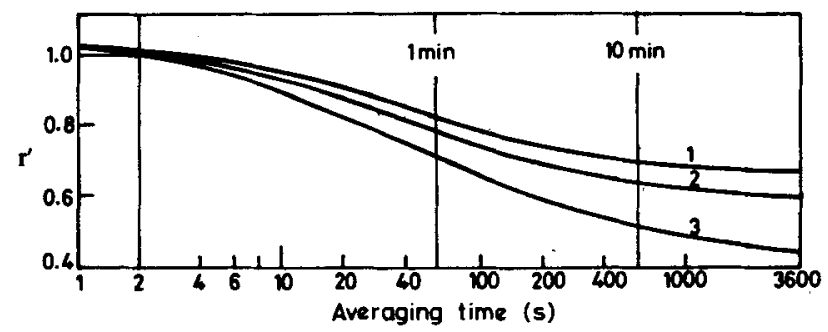

Figure 7. Ratio, $r$, of maximum probable wind speeds averaged over $t s$ to those averaged over $2 \mathrm{~s}$ (Source: Simiu 1977) 1: Open terrain $\left(z_{0}=0.003-0.008 \mathrm{~m}\right) 2$ : Wooded and for low built up buildings in small towns $\left(z_{0}=0.15-0.30 \mathrm{~m}\right) 3:$ Large city centres $\left(z_{0}=1.00 \mathrm{~m}\right)$ (see table 6 for the definition of $z_{0}$ ) 
Table 4. Coefficients for the determination of extreme wind speeds for given return period $T(\mathrm{yr})$.

\begin{tabular}{|c|c|c|}
\hline Station & a & b \\
\hline Ahmedabad & $22 \cdot 7$ & $21 \cdot 5$ \\
\hline Allahabad & $24 \cdot 3$ & $23 \cdot 3$ \\
\hline Amritsar & $34 \cdot 4$ & 60 \\
\hline Bangalore & $22 \cdot 1$ & $8 \cdot 7$ \\
\hline Baroda & $18 \cdot 1$ & $7 \cdot 4$ \\
\hline Bhopal & $25 \cdot 5$ & 10.8 \\
\hline Bombay & $23 \cdot 3$ & $13 \cdot 0$ \\
\hline Calcutta & $30 \cdot 1$ & 147 \\
\hline Cochin* & $17 \cdot 4$ & $12 \cdot 0$ \\
\hline Gaya & 25.9 & $15 \cdot 3$ \\
\hline Gopalpur & $25 \cdot 9$ & $15 \cdot 3$ \\
\hline Hyderabad & $24 \cdot 7$ & $19 \cdot 4$ \\
\hline Jagdalpur & $21 \cdot 7$ & $14 \cdot 4$ \\
\hline Jaipur & 21.4 & $21 \cdot 0$ \\
\hline Jamshedpur & 27.9 & $21 \cdot 7$ \\
\hline Jodhpur & $26 \cdot 3$ & $20-8$ \\
\hline Kodaikanal & $24 \cdot 6$ & $8 \cdot 4$ \\
\hline Lucknow & $24 \cdot 4$ & 12.9 \\
\hline Madras & $23 \cdot 3$ & 160 \\
\hline Nagpur & $27 \cdot 1$ & $15 \cdot 4$ \\
\hline New Delhi & $29 \cdot 3$ & 17.2 \\
\hline Pune & $22 \cdot 6$ & 14.8 \\
\hline Port Blair & $26 \cdot 7$ & $12 \cdot 3$ \\
\hline Sagar Island & $27 \cdot 1$ & $12 \cdot 1$ \\
\hline Tiruchirapalli* & 27.5 & $13 \cdot 7$ \\
\hline Trivandrum* & 16.9 & $14 \cdot 3$ \\
\hline Tuticorin* & $24 \cdot 8$ & 6.5 \\
\hline Veraval & $24 \cdot 7$ & 14.0 \\
\hline
\end{tabular}

The extreme wind speed for a return period of $T$ years is given by

$$
V_{T}=a+b y(T), \quad V_{T} \text { in } \mathrm{m} / \mathrm{s} ; \quad y(T)=-\ln (-\ln (1-(1 / T)) .
$$

*Stations taken from Narasimha \& Shrinivasa (1983); rest of the stations are from Ayyar \& Goyal (1972).

Table 5. Design return periods for specified risk of failure.

\begin{tabular}{|c|c|c|c|c|c|c|c|c|c|}
\hline \multirow{2}{*}{$\begin{array}{l}\text { Life } \\
\text { (yr) }\end{array}$} & \multicolumn{9}{|c|}{ Design return period (yr) for failure risk = } \\
\hline & $0 \cdot 1$ & 0.2 & $0 \cdot 3$ & 0.4 & 0.5 & 0.6 & 0.7 & 0.8 & 0.9 \\
\hline 2 & 19 & 9 & 6 & $4 \cdot 4$ & $3 \cdot 4$ & $2 \cdot 7$ & $2 \cdot 2$ & 1.8 & 1.5 \\
\hline 5 & 48 & 23 & 14 & 10 & 8 & 6 & $4 \cdot 7$ & 3.6 & $2 \cdot 7$ \\
\hline 10 & 95 & 45 & 29 & 20 & 15 & 11 & 9 & 6.7 & 4.9 \\
\hline 15 & 114 & 68 & 43 & 30 & 22 & 17 & 13 & 10 & 7 \\
\hline 20 & 190 & 90 & 57 & 40 & 29 & 22 & 17 & 13 & 7 \\
\hline 25 & 234 & 112 & 71 & 49 & 37 & 28 & 21 & 16 & 11 \\
\hline 50 & 475 & 225 & 141 & 98 & 72 & 55 & 40 & 32 & 22 \\
\hline 100 & 950 & 449 & 281 & 196 & 145 & 110 & 54 & 63 & 44 \\
\hline
\end{tabular}




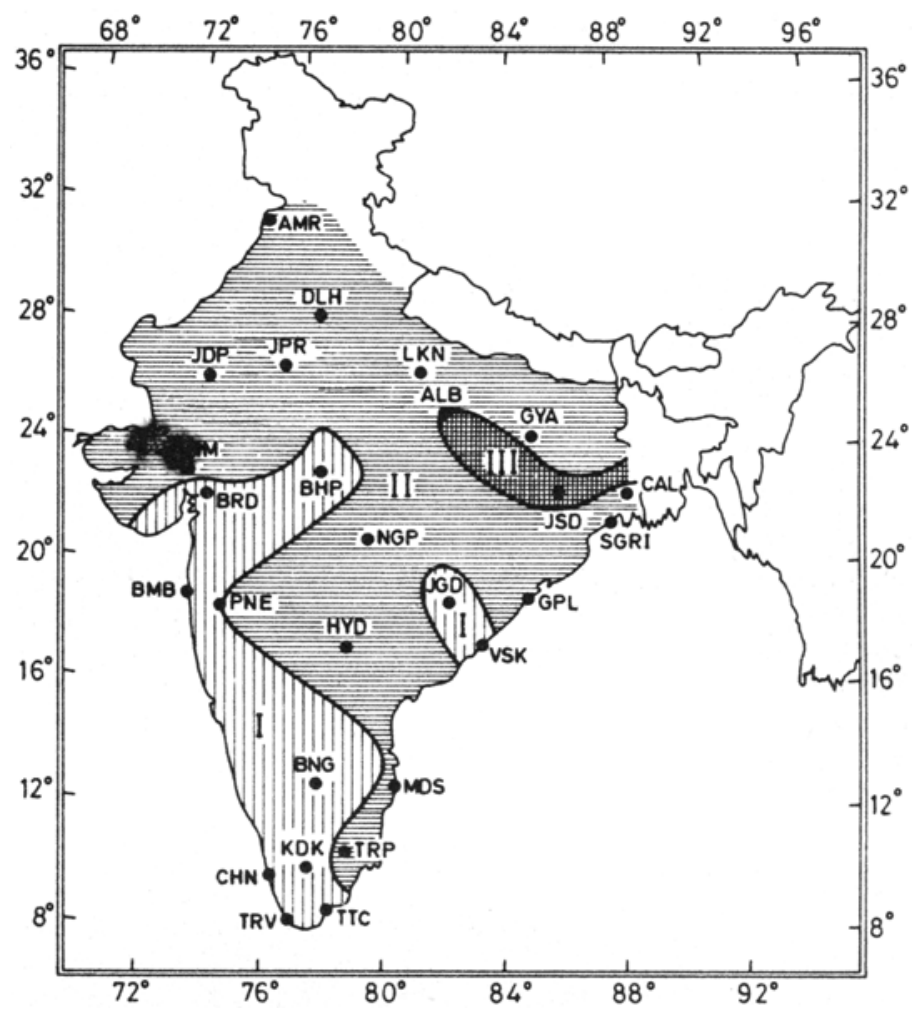

Figure 8. Tentative proposal for design wind zones for India-50 yr return period

Table 6. Classification of terrain based on equivalent roughness height.

\begin{tabular}{lc}
\hline Type of exposure & $\begin{array}{c}\text { Suggested values } \\
\text { of } z_{0}(\mathbf{m})\end{array}$ \\
\hline Coastal & $0.005-0.01$ \\
Open & $0.03-0.10$ \\
Outskirts of towns, suburbs & $0.20-0.30$ \\
Centres of towns & $0.35-0.45$ \\
Centres of large cities & $0.60-0.80$ \\
\hline
\end{tabular}

Note: Wind speeds $V_{1}$ and $V_{2}$ at heights $z_{1}$ and $z_{2}$ above the ground level are related as follows.

$$
V_{1} / V_{2}=\ln \left(\left(z_{1}-z_{d}\right) / z_{0}\right) / \ln \left(\left(z_{2}-z_{d}\right) / z_{0}\right)
$$

where $z_{0}$ is as given above and $z_{d}$ may in all cases be assumed to be zero, except that in cities (or in wooded terrain) $z_{d}=0.75 \times$ average height of buildings (trees) in the surrounding area.

(Source: Simiu 1977). 


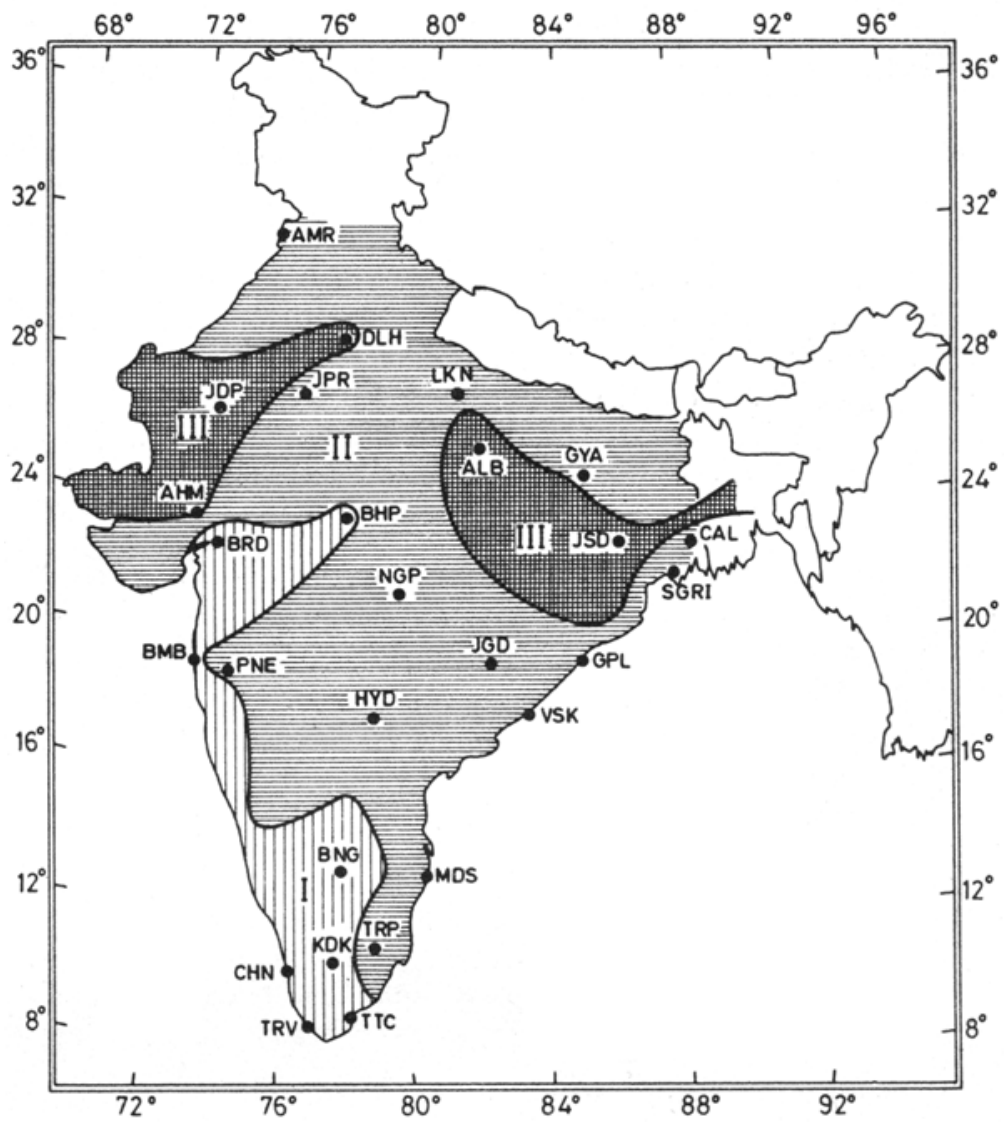

Figare 9. Tentative proposal for design wind zones for India-100 yr return period.

Table 7. Tentative values of design wind speeds $(\mathrm{m} / \mathrm{s})$ for India.

\begin{tabular}{lcc}
\hline & $\begin{array}{c}50 \text { yr return } \\
\text { period }\end{array}$ & $\begin{array}{c}100 \text { yr return } \\
\text { period }\end{array}$ \\
\hline zone I & $40 \mathrm{~m} / \mathrm{s}$ & $40 \mathrm{~m} / \mathrm{s}$ \\
zoone II & $50 \mathrm{~m} / \mathrm{s}$ & $50 \mathrm{~m} / \mathrm{s}$ \\
zone III & $60 \mathrm{~m} / \mathrm{s}$ & $60 \mathrm{~m} / \mathrm{s}$ \\
\hline
\end{tabular}

these modifications to be consistent with the present proposals in the sense that structures designed on the basis of the proposed maps are likely to remain safe according to any later modifications.

\section{Conclusions}

Details presented in the foregoing sections indicate that sufficient knowledge is available today for a more rational analysis of the wind loads that buildings and 
structures would experience in their life time. If India decides to recommend such analysis to her designers, it will not be difficult to formulate a tentative code using the data available and casting them into a standard form for this purpose.

However, it may be necessary to pay adequate attention to the various meteorological phenomena peculiar to the Indian sub-continent, which may have relevance to the analysis: for example, nor'westers or kal baisakhis in the Gangetic plain. Further, since the procedures proposed in the codes of other countries have not been validated for India, it may be necessary to modify them as more experience is gained within the country with their use.

It would also be of great value to analyse reported failures of wind mills and tall structures in the country to examine whether there is a correlation with the high-wind zones mapped in this paper.

The work reported here was carried out under a project "Design, Fabrication and Testing of a 10,000 litres/hour Windpump", financed and administered by the Karnataka State Council for Science and Technology, Indian Institute of Science, Bangalore. The authors are grateful to the KSCST for the support received from them and to Ms B Savita for the assistance provided during the preparation of this paper.

\section{References}

Ananthasayanam M R, Narasimha R 1980 Standards for the tropical Indian atmosphere, Space Res. 20: 25-28; also Report 80 FM 3, Department of Aerospace Engineering. Indian Institute of Science, Bangalore

Ayyar P S H, Goyal S C 1972 Indian J. Meteorol. Geophys. 23: 67-70

E S D U 1972 onwards, Engg. science data, Fluid mechanics, external flow (London: Engg. Science Data Unit Ltd.)

Gumbel E J 1958 Statistics of extremes (New York: Columbia University Press)

Indian Standards Institution 1965 Code of Practice for Structural Safety of Buildings, Loading Standards, IS: 875-1964, New Delhi

Lawson T V 1980 Wind effects on buildings (London: Applied Science Publishers) Vol. 1 \& 2

Mani A, Mooley D A 1983 Wind energy data for India (New Delhi: Allied Publishers)

Mikhail A S 1981 Windpower for developing countries, SERI/TR-762-966, SERI, Golden Colorado

Narasimha R, Srinivasa U 1983 Wind zones for India, Report 83 FM 6, Department of Aerospace Engineering, Indian Institute of Science, Bangalore

N B C 1970 National Building Code, Indian Standards Institution, New Delhi

Sharma B L, Sehgal U N 1968 Indian J. Meteorol. Geophys. 27: 319-322

Shrinivasa U 1984 Wind and atmosphere J. Inst. Eng., India (to be published)

Simiu E 1977 in Building to resist the effect of wind (Washington: N B S Building Science Series 100-2) Vol. 2

Thom H C S 1967 Second Int. Conf. on wind effects on buildings and structures (Ottawa: University of Toronto Press) 